\title{
Iron oxide nanozyme catalyzed synthesis of fluorescent polydopamine for light-up $\mathrm{Zn}^{2+}$ detection
}

\author{
Biwu Liu, Xiao Han, and Juewen Liu* \\ Department of Chemistry, Waterloo Institute for Nanotechnology, \\ University of Waterloo, Waterloo, Ontario, Canada, N2L 3G1.
}

Email: liujw@uwaterloo.ca 


\begin{abstract}
Fluorescent polydopamine (FPD) is an interesting material with excellent biocompatibility. However, its preparation is currently a lengthy and potentially dangerous process. We herein employ magnetic iron oxide $\left(\mathrm{Fe}_{3} \mathrm{O}_{4}\right)$ nanoparticles as a peroxidase-mimicking nanozyme to produce FPD under mild conditions. Different from previous protocols using multiple steps with up to $6 \%(\sim 2 \mathrm{M}) \mathrm{H}_{2} \mathrm{O}_{2}$, this preparation takes place in a single step with just $5 \mathrm{mM} \mathrm{H}_{2} \mathrm{O}_{2}$ at room temperature. The oxidized product shows excitationwavelength-dependent emission peaks, similar to previous reports. The reaction kinetics, $\mathrm{pH}$, temperature, and ionic strength are individually optimized. Among a diverse range of other nanomaterials tested, including $\mathrm{Fe}_{2} \mathrm{O}_{3}, \mathrm{CeO}_{2}, \mathrm{CoO}, \mathrm{Co}_{3} \mathrm{O}_{4}, \mathrm{NiO}, \mathrm{TiO}_{2}$, gold nanoparticles, and graphene oxide, $\mathrm{Fe}_{2} \mathrm{O}_{3}$ and graphene oxide also yielded relatively weak emission, while the rest of the materials failed to produce FPD. The $\mathrm{Fe}_{3} \mathrm{O}_{4}$ nanoparticles retained $\sim 90 \%$ catalytic activity even after ten cycles of synthesis. Finally, $\mathrm{Zn}^{2+}$ can enhance the fluorescence of FPD under $360 \mathrm{~nm}$ excitation but not under $480 \mathrm{~nm}$ excitation,

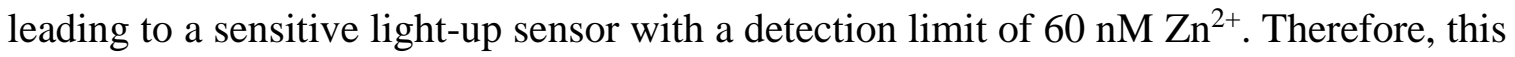
work has demonstrated not only a novel use of nanozyme, but also an interesting application for FPD.
\end{abstract}




\section{Introduction}

Dopamine is a well-known neurotransmitter. Aside from its biological importance, it is also an intriguing molecule far from being fully understood. Dopamine can be oxidized and polymerized in alkaline conditions to form polydopamine. ${ }^{1,2}$ Due to its excellent biocompatibility, polydopamine has been extensively investigated for surface coating, ${ }^{2}$ molecular imprinting, ${ }^{3}$ and biosensing. ${ }^{4}$ Recently, polydopamine was found to be fluorescent under certain conditions. For example, Zhang and co-workers obtained fluorescent polydopamine (FPD) nanoparticles (NPs) by treating polydopamine with concentrated $\mathrm{H}_{2} \mathrm{O}_{2}{ }^{5}$ The resulting FPD exhibited excitation-wavelength-dependent emission, and it was used for cell imaging. Using a similar method, FPD capsules were formed on $\mathrm{SiO}_{2}$ and $\mathrm{CaCO}_{3}$ templates. ${ }^{6}$ Yildirim et al. determined that FPD is an intermediate during the dopamine auto-oxidation process in alkaline conditions. ${ }^{7}$ Hydroxyl radicals generated by the Fenton agent $\left(\mathrm{Fe}^{2+}-\mathrm{H}_{2} \mathrm{O}_{2}\right)$ was also effective in degrading polydopamine. ${ }^{8}$ However, all these methods require concentrated $\mathrm{H}_{2} \mathrm{O}_{2}$ (e.g. up to $6 \%$ ). The resulting harmful free radicals may limit the application of FPD, and concentrated $\mathrm{H}_{2} \mathrm{O}_{2}$ also poses a safety hazard.

The involvement of $\mathrm{H}_{2} \mathrm{O}_{2}$ for producing fluorescent materials suggests a possibility of accelerating the reaction by using a peroxidase. Nanozymes are nanomateirals with enzyme-like activities. ${ }^{9-12}$ Noble metals, ${ }^{13-15}$ carbons, ${ }^{16-18}$ and metal oxides ${ }^{19-24}$ have been demonstrated to mimic oxidase, peroxidase, catalase, and/or superoxide dismutase enzymes. Among these nanozymes, iron oxide is particularly interesting due to its unique magnetic property. ${ }^{20,25-27}$ Since the first report by Yan and co-workers, ${ }^{20}$ iron oxide peroxidase nanozymes have been extensively studied. Some applications include the 
detection of $\mathrm{H}_{2} \mathrm{O}_{2}$ and glucose, ${ }^{27}$ nerve agents, ${ }^{25}$ and Ebola virus. ${ }^{28}$ To assay the peroxidase-like activity of iron oxide NPs, chromogenic substrates were commonly used. Dopamine was also used as such a substrate. ${ }^{29,30}$ Typically, the reaction is carried out at low $\mathrm{pH}$, and oxidized dopamine appears yellow. However, no fluorescence was reported for such products. Therefore, we are interested in testing a new application of iron oxide nanozymes in this work: preparing FPD under milder conditions. We also report that FPD can be used for highly sensitive $\mathrm{Zn}^{2+}$ detection.

\section{Materials and Methods}

Chemicals. Dopamine hydrochloride, hydrogen peroxide (30 wt\%), 3,3',5,5'tetramethylbenzidine (TMB), iron(III) chloride, iron(II) chloride, cobalt(II) chloride, nickel chloride, copper sulfate, zinc chloride, manganese(II) chloride, lead acetate, and mercury chloride were acquired from Sigma-Aldrich (St. Louis, MO, USA). Sodium acetate, 4-(2-hydroxyethyl) piperazine-1-ethanesulfonic acid (HEPES), sodium acetate, 4(2-hydroxyethyl) piperazine-1-ethanesulfonic acid (HEPES), 2-(N-morpholino) ethanesulfonic acid (MES) were from Mandel Scientific (Guelph, ON, Canada).were from Mandel Scientific (Guelph, ON, Canada). Nanoceria dispersion (catalog number 289744, 20 wt $\%$ dispersed in $2.5 \%$ acetic acid $), \mathrm{Fe}_{3} \mathrm{O}_{4} \mathrm{NPs}(<50 \mathrm{~nm}$, catalog number 637106), and $\mathrm{TiO}_{2}$ NPs (25 nm, catalog number 637254) were purchased from Sigma. CoO (50 nm, US3051), $\mathrm{Co}_{3} \mathrm{O}_{4}(10-30 \mathrm{~nm}, \mathrm{US} 3056), \mathrm{NiO}(10-20 \mathrm{~nm}, \mathrm{US} 3356)$ were from US Nano Research. Citrate-capped AuNPs $(\sim 13 \mathrm{~nm})$ were prepared based on literature. ${ }^{31}$ Graphene oxide (GO) was purchased from ACS Material, LLC (Medford, MA, USA). Milli-Q water was used for all of the experiments. 
Instrumentation. The UV-vis absorption spectra were recorded on an UV-vis spectrometer (Agilent 8453A). The transmission electronic microscopy was performed using a Philips CM10 microscope. The fluorescence measurements were carried out using a Varian Eclipse fluorescence spectrometer (Agilent Technologies, Santa Clara, CA).

Preparation of FPD. In a typical synthesis, freshly prepared dopamine $(0.5 \mathrm{mM})$ was incubated with $\mathrm{H}_{2} \mathrm{O}_{2}(5 \mathrm{mM})$ in the presence of $\mathrm{Fe}_{3} \mathrm{O}_{4} \mathrm{NPs}(0.5 \mathrm{mg} / \mathrm{mL})$ in the acetate buffer ( $\mathrm{pH} 4,50 \mathrm{mM}$ ) for $2 \mathrm{~h}$. Occasional vertex was performed to avoid the precipitation of $\mathrm{Fe}_{3} \mathrm{O}_{4}$ NPs. After separating $\mathrm{Fe}_{3} \mathrm{O}_{4}$ NPs by a magnet, the supernatant containing FPD was collected for further measurement. The kinetics of fluorescence generation was recorded by measuring the fluorescent spectra of the supernatant at designated time points. Effect of nanomaterials. The dopamine oxidation in the presence of different nanomaterials was carried out in a similar way. The concentration of metal oxide NPs was $0.5 \mathrm{mg} / \mathrm{mL}$, AuNPs $5 \mathrm{nM}$, and GO $0.1 \mathrm{mg} / \mathrm{mL}$. After $2 \mathrm{~h}$ reaction, the nanomaterials were separated by centrifugation (15 $000 \mathrm{rpm}, 15 \mathrm{~min}$ ) and the supernatant was collected for further measurement.

Optimization of synthesis. The $\mathrm{pH}$ effect was investigated by incubating dopamine, $\mathrm{Fe}_{3} \mathrm{O}_{4}$ NPs, and $\mathrm{H}_{2} \mathrm{O}_{2}$ at $\mathrm{pH} 4$ (acetate buffer), pH 5 (acetate buffer), $\mathrm{pH} 6$ (MES buffer), $\mathrm{pH} 7$ (HEPES buffer), pH 8 (HEPES buffer), and pH 8.5 (Tris buffer) for 2 h. The buffer concentration was $50 \mathrm{mM}$. The effect of ionic strength was examined by adding $\mathrm{NaCl}$ to the buffer solution ( $\mathrm{pH} 4$ acetate buffer, $50 \mathrm{mM}$ ). The fluorescence spectra after $2 \mathrm{~h}$ reaction were recorded. To test the temperature effect, the reaction mixture was incubated at different temperatures $\left(4^{\circ} \mathrm{C}\right.$ in a fridge, $15-65^{\circ} \mathrm{C}$ in a water bath). After $1 \mathrm{~h}$ reaction, the fluorescence spectra were recorded. 
Stability of FPD. The stability was examined by respectively incubating the prepared FPD at different $\mathrm{pH}(4,5,6,7,7.6$, and 8.5), $\mathrm{NaCl}$ concentration $(0,50,100,250$, and $500 \mathrm{mM})$, and divalent metal ions $\left(\mathrm{Mg}^{2+}, \mathrm{Ca}^{2+}, \mathrm{Sr}^{2+}, \mathrm{Ba}^{2+}, 1 \mathrm{mM}\right.$ each) overnight. Typically, $50 \mu \mathrm{L}$ of the prepared FPD in acetate buffer $(10 \mathrm{mM}, \mathrm{pH}$ 4) was added into $50 \mu \mathrm{L}$ of buffer solutions $(100 \mathrm{mM})$ with designed $\mathrm{pH}$ or salt. The fluorescence spectra were then recorded. $\mathbf{Z n}^{2+}$ detection. To test metal selectivity, $50 \mu \mathrm{L}$ of the prepared FPD was respectively incubated with various metal ions $\left(10 \mu \mathrm{M}\right.$ each), including $\mathrm{Fe}^{3+}, \mathrm{Fe}^{2+}, \mathrm{Co}^{2+}, \mathrm{Ni}^{2+}, \mathrm{Cu}^{2+}$, $\mathrm{Zn}^{2+}, \mathrm{Mn}^{2+}, \mathrm{Pb}^{2+}$, and $\mathrm{Hg}^{2+}$ in HEPES buffer ( $\mathrm{pH} 7.6,50 \mathrm{mM}$ ). The fluorescence emission spectra were recorded under two excitation wavelengths ( $360 \mathrm{~nm}$ and $480 \mathrm{~nm}$ ). To test the

sensitivity for $\mathrm{Zn}^{2+}$ detection, $20 \mu \mathrm{L}$ of FPD was mixed with different concentrations of $\mathrm{Zn}^{2+}$ in HEPES buffer (pH 7.6, $50 \mathrm{mM}$ ). After $3 \mathrm{~min}$, the fluorescence intensity at $500 \mathrm{~nm}$ (excitation at $360 \mathrm{~nm}$ ) was recorded.

\section{Results and Discussion}

\section{Synthesis of FPD with $\mathrm{Fe}_{3} \mathrm{O}_{4}$ nanozyme.}

So far, only a few papers reported the synthesis of fluorescent polydopamine (FPD). While these protocols vary quite a bit, they generally involve two steps. 1) Polymerizing dopamine into polydopamine under basic conditions. In this process, dopamine is oxidized by oxygen. 2) $\mathrm{H}_{2} \mathrm{O}_{2}$ is then added to further oxidize or break polydopamine to FPD. This step often employs a high concentration (e.g. $6 \%$ or $\sim 2 \mathrm{M}$ ) of $\mathrm{H}_{2} \mathrm{O}_{2} .{ }^{5}$ Therefore, it is desirable to reduce the $\mathrm{H}_{2} \mathrm{O}_{2}$ concentration during the synthesis. In the past decade, it has become clear that iron oxide NPs are efficient peroxidase mimicking nanozymes. We 
hypothesize that by providing a nanozyme surface for localized oxidation, one-step synthesis of FPD might be achieved as depicted in Figure 1A.

To test this idea, dopamine was incubated with $\mathrm{H}_{2} \mathrm{O}_{2}$ in the presence of $\mathrm{Fe}_{3} \mathrm{O}_{4}$ NPs. Our $\mathrm{Fe}_{3} \mathrm{O}_{4}$ NPs have an average size of $25 \mathrm{~nm}$ as indicated by TEM (Figure S1). After overnight incubation at room temperature, a yellow color was developed (inset of Figure 1B), suggesting oxidation of dopamine. ${ }^{1,29}$ The sample was characterized by UV-vis absorption spectroscopy, and a peak centered at $450 \mathrm{~nm}$ was obtained (Figure 1B, blue curve). Control samples of free dopamine, dopamine with $\mathrm{H}_{2} \mathrm{O}_{2}$ alone, and dopamine mixed with $\mathrm{Fe}_{3} \mathrm{O}_{4}$ NPs alone were also prepared. No color change or absorption peaks in the visible region were found for these control samples. It needs to be pointed out that we used only $5 \mathrm{mM} \mathrm{H}_{2} \mathrm{O}_{2}$ here, which is $\sim 400$-fold lower compared to the previous reported methods $\left(6 \% \mathrm{H}_{2} \mathrm{O}_{2}=1.96 \mathrm{M}\right){ }^{5}$

The oxidation of dopamine by $\mathrm{H}_{2} \mathrm{O}_{2}$ using natural protein enzymes or nanozymes was observed by several groups. ${ }^{29,32}$ However, none of these papers mentioned the fluorescence property of the oxidation products. For the four samples we prepared above, a green/yellow fluorescence was observed for the one with both $\mathrm{H}_{2} \mathrm{O}_{2}$ and $\mathrm{Fe}_{3} \mathrm{O}_{4} \mathrm{NPs}$ when excited at $470 \mathrm{~nm}$ (inset of Figure 1C). We also recorded the fluorescence spectra, and this sample showed an emission peak at $530 \mathrm{~nm}$ (Figure 1C, excitation $480 \mathrm{~nm}$ ). When excited at different wavelengths, the emission peaks were also shifted accordingly (Figure 1D). This result is similar to the FPD reported by other groups. ${ }^{5,7,8}$ Such a property suggests the complexity of dopamine oxidation by $\mathrm{H}_{2} \mathrm{O}_{2}$, yielding a mixture. Each type of molecule in this mixture has its own optimal excitation and emission wavelength, which is likely due to the different degree of polymerization. The strongest emission was obtained when 
exciting the sample at $480 \mathrm{~nm}$ (Figure S2). All the control samples failed to show any fluorescence. Therefore, the $\mathrm{Fe}_{3} \mathrm{O}_{4}$ nanozyme can indeed achieve one-pot production of FPD under mild conditions. We characterized our FPD using TEM (Figure S3). Particles from a few to $15 \mathrm{~nm}$ were observed, consistent with a broad size distribution from the above fluorescence characterization. The quantum yield of our FPD is 1.0\% (Figure S4), which is similar to the value $(1.2 \%)$ reported by Lin et al. ${ }^{8}$
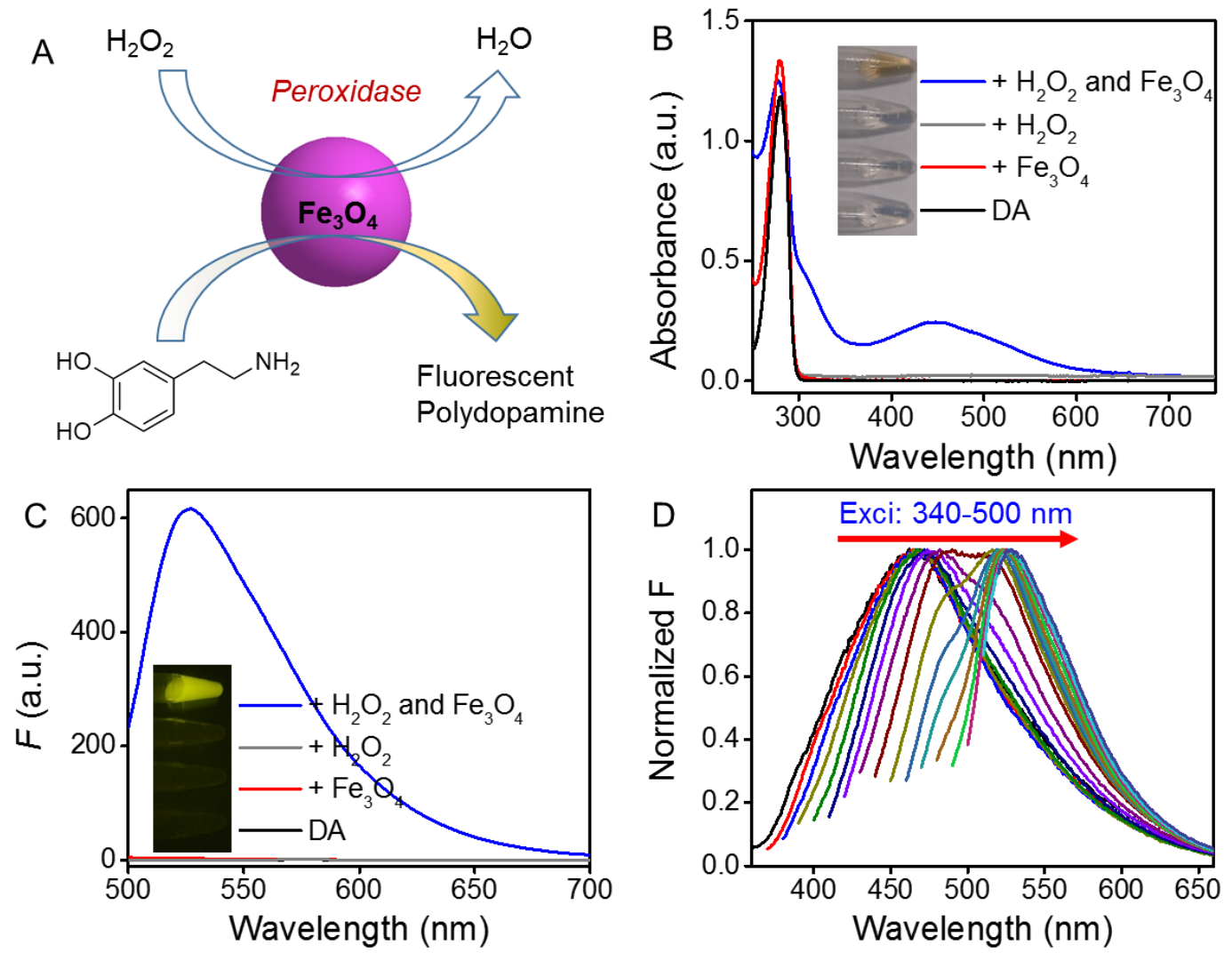

Figure 1. (A) Schematic representation of preparation of FPD using $\mathrm{Fe}_{3} \mathrm{O}_{4} \mathrm{NPs}$ as a peroxidase mimicking nanozyme. (B) UV-vis absorption and (C) fluorescence emission spectra (excitation at $480 \mathrm{~nm}$ ) of our prepared FPD and the control samples omitting $\mathrm{H}_{2} \mathrm{O}_{2}$ or $\mathrm{Fe}_{3} \mathrm{O}_{4}$ or both. $\mathrm{DA}=$ dopamine. The inset photographs are the dopamine samples $(\mathrm{B})$ 
under ambient light, and (C) under $470 \mathrm{~nm}$ LED excitation in a dark room. (D) Normalized FPD emission spectra at various excitation wavelengths.

\section{Effect of other nanozymes}

Many inorganic NPs have been reported to possess peroxidase-like activity. ${ }^{10} \mathrm{We}$ chose $\mathrm{Fe}_{3} \mathrm{O}_{4}$ since it is a well-known peroxidase mimic with magnetic property. Similar to $\mathrm{Fe}_{3} \mathrm{O}_{4}$, $\mathrm{Fe}_{2} \mathrm{O}_{3}$ can also catalyze dopamine peroxidation and the product is fluorescent (Figure S5). To test if other NPs can also be used, we next carried the reaction in the presence of a few common nanomaterials, including $\mathrm{CeO}_{2}, \mathrm{CoO}, \mathrm{Co}_{3} \mathrm{O}_{4}, \mathrm{NiO}, \mathrm{TiO}_{2}$, gold nanoparticles (AuNPs), and graphene oxide (GO). Two nanozyme activities were respectively assayed: oxidase and peroxidase. Both assays used the same chromogenic substrate, 3,3',5,5'tetramethylbenzidine (TMB). $\mathrm{CeO}_{2}, \mathrm{CoO}$, and $\mathrm{NiO}$ induced $\mathrm{TMB}$ oxidation in the absence of $\mathrm{H}_{2} \mathrm{O}_{2}$ and thus they are oxidase mimics (Figure 2A). Similarly, these three metal oxides also oxidized dopamine in the absence of $\mathrm{H}_{2} \mathrm{O}_{2}$, as indicated by the yellow color (Figure 2B, Figure S6A). However, such oxidized products are non-fluorescent (Figure 2C,D).

All these materials (except for $\mathrm{TiO}_{2}$ ) catalyzed TMB oxidation in the presence of $\mathrm{H}_{2} \mathrm{O}_{2}$ (Figure 2E), suggesting that they are peroxidase mimics. Indeed, these peroxidase mimics also catalyzed the peroxidation of dopamine (Figure 2F, Figure S6B). Fluorescence measurement, however, showed that only $\mathrm{GO}$ and $\mathrm{Fe}_{3} \mathrm{O}_{4} \mathrm{NPs}$ yielded FPD. The efficiency of GO is much lower than that of $\mathrm{Fe}_{3} \mathrm{O}_{4}$ NPs. Since GO is a single-layered material, its surface area is much larger compared to that of the $\mathrm{Fe}_{3} \mathrm{O}_{4} \mathrm{NPs}$. The fact that $\mathrm{Fe}_{3} \mathrm{O}_{4}$ still produced stronger fluorescence indicates that $\mathrm{Fe}_{3} \mathrm{O}_{4} \mathrm{NPs}$ are optimal for catalyzing this reaction. The exact mechanism for favoring $\mathrm{Fe}_{3} \mathrm{O}_{4}$ remains unclear. It might be related to 
the preferential binding of the dopamine catechol groups to the $\mathrm{Fe}^{3+}$ sites on the $\mathrm{Fe}_{3} \mathrm{O}_{4}$ NPs. ${ }^{33}$
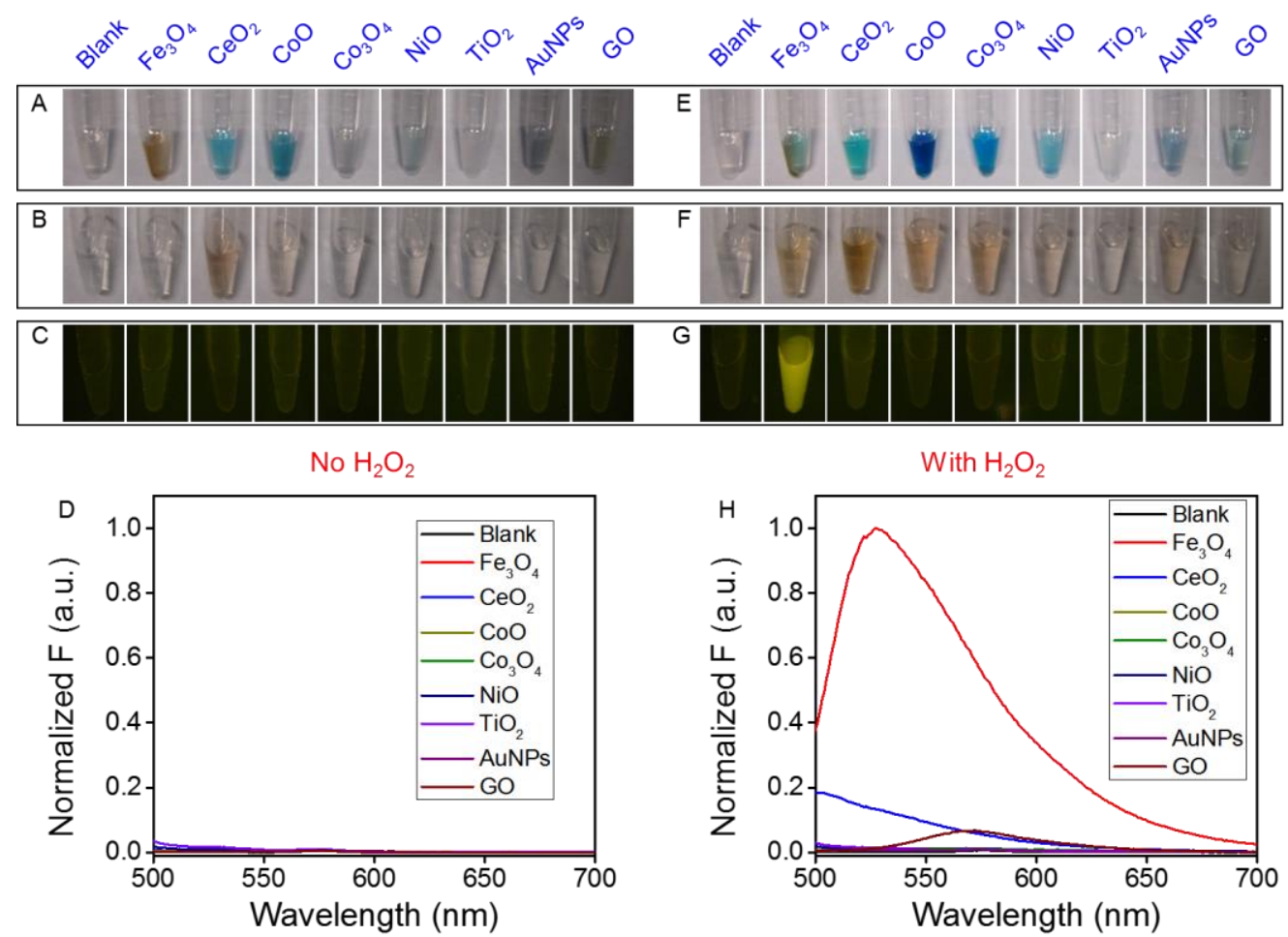

Figure 2. Images of oxidized TMB (A, E), and oxidized dopamine $(B, F)$ under visible light, and the fluorescence of oxidized dopamine under $470 \mathrm{~nm}$ excitation $(\mathrm{C}, \mathrm{G})$. Fluorescent spectra of dopamine incubated with these nanomaterials (D) in the absence of $\mathrm{H}_{2} \mathrm{O}_{2}$ and $(\mathrm{H})$ in the presence of $\mathrm{H}_{2} \mathrm{O}_{2}$. The concentration of metal oxides was $500 \mu \mathrm{g} / \mathrm{mL}$, AuNPs $=5 \mathrm{nM}$, and graphene oxide $=0.2 \mathrm{mg} / \mathrm{mL}$. The reactions shown in $(\mathrm{A}-\mathrm{D})$ and $(\mathrm{E}-$ $\mathrm{H})$ panels were carried out in the absence and presence of $\mathrm{H}_{2} \mathrm{O}_{2}$, respectively. The TMB $(0.5 \mathrm{mM})$ or dopamine $(0.5 \mathrm{mM})$ oxidation reactions were carried out at $\mathrm{pH} 4$ (acetate buffer, $50 \mathrm{mM}$ ) in the presence of optional $20 \mathrm{mM}$ and $5 \mathrm{mM} \mathrm{H}_{2} \mathrm{O}_{2}$, respectively. The images were taken after $30 \mathrm{~min}$ of reaction. 


\section{Nanozyme recycling}

One concern of using NPs to catalyze dopamine oxidation is surface deactivation by forming a polydopamine shell. For example, dopamine was reported to form a fluorescent shell on other materials such as $\mathrm{SiO}_{2}$ and $\mathrm{CaCO}_{3} .{ }^{6}$ In general, dopamine has strong affinity to many surfaces, ${ }^{2}$ and it can even stabilize iron oxide NPs. ${ }^{33}$ To test whether a surface coating is formed in our system, we examined the recycling ability of $\mathrm{Fe}_{3} \mathrm{O}_{4} \mathrm{NPs}$ in producing FPD. The fluorescence intensity of the oxidization products after ten reaction cycles still remained $90 \%$ of the value of the fresh $\mathrm{Fe}_{3} \mathrm{O}_{4}$ NPs (Figure 3A). Such high reusability of $\mathrm{Fe}_{3} \mathrm{O}_{4} \mathrm{NPs}$ argues against surface deactivation. TEM also failed to show any observable polymer shell features on the $\mathrm{Fe}_{3} \mathrm{O}_{4} \mathrm{NPs}$ after the dopamine oxidation reaction, further supporting the lack of product adsorption (Figure 3B). Finally, $\mathrm{Fe}_{3} \mathrm{O}_{4}$ is a strong fluorescence quencher,(cite your arsenate Chem. Commun. Paper) and we expect FDP emission to be quenched if it adsorbed on the particle surface. Taken together, this study also highlights that $\mathrm{Fe}_{3} \mathrm{O}_{4} \mathrm{NPs}$ is a recyclable catalyst with high catalytic turnovers.
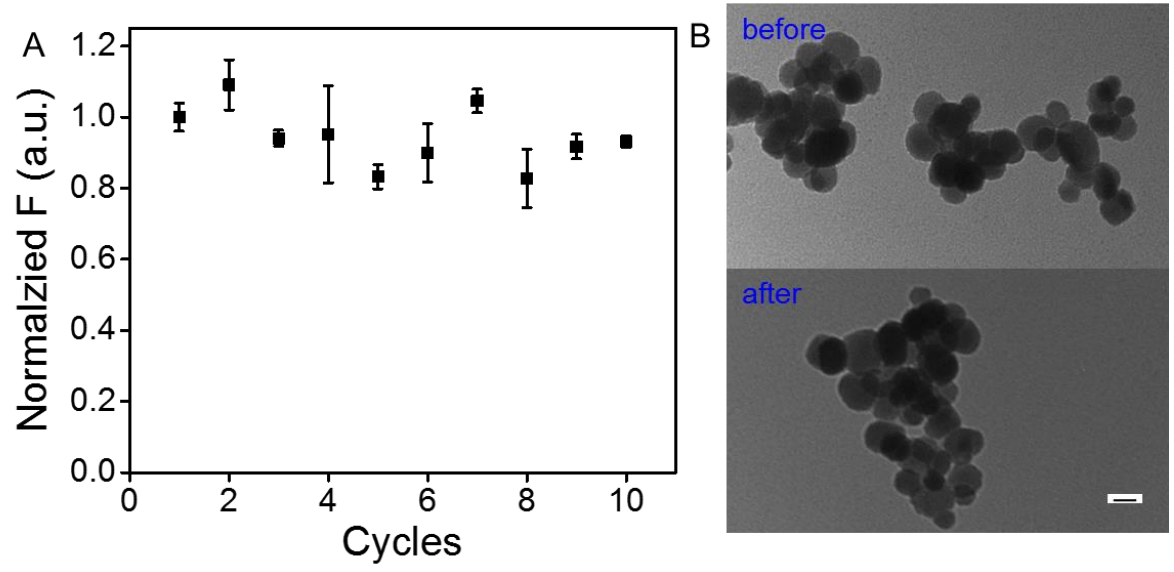

Figure 3. (A) The reusability of $\mathrm{Fe}_{3} \mathrm{O}_{4} \mathrm{NPs}$ in catalyzing dopamine oxidation. The fluorescent intensity $525 \mathrm{~nm}$ after each cycle is plotted. The error bars represent standard 
deviations from three independent measurements. (B) TEM micrographs of $\mathrm{Fe}_{3} \mathrm{O}_{4} \mathrm{NPs}$ before and after the dopamine oxidation reaction. The scale bar is $20 \mathrm{~nm}$.

\section{Optimization of oxidation conditions}

Since the $\mathrm{Fe}_{3} \mathrm{O}_{4}$ NPs appear to be a highly efficient catalyst for producing FPD, we next aim to further optimize its oxidization reaction. In the same process, we may gain new mechanistic insights. First, the reaction kinetic was studied. The fluorescence spectra of the sample containing dopamine, $\mathrm{H}_{2} \mathrm{O}_{2}$ and $\mathrm{Fe}_{3} \mathrm{O}_{4}$ NPs were measured at different time points (Figure 4A). A gradual increase in fluorescence was observed over time, and saturated intensity was reached after $2 \mathrm{~h}$ (inset), which is faster than the previous protocols taking $5 \mathrm{~h}^{5}{ }^{5}$ The emission peaks showed a slight blue shift in this process, suggesting the breaking down of FPD into smaller molecular weight products with continuous reaction.

The nanozyme activity might also be affected by temperature. Compared to natural enzymes, which work optimally at the body temperature, an advantage of nanozymes is stability over a wide temperature range. We carried out the reaction at different temperatures and recorded the fluorescence spectra after $1 \mathrm{~h}$ reaction (Figure 4B). The highest activity was exhibited at $65^{\circ} \mathrm{C}$. At even higher temperature, the fluorescence yield dropped, possibly due to non-specific breaking down or evaporation of $\mathrm{H}_{2} \mathrm{O}_{2}$ (note that we only used $5 \mathrm{mM} \mathrm{H}_{2} \mathrm{O}_{2}$ ).

The effect of $\mathrm{pH}$ on the production of FPD was examined next. $\mathrm{Fe}_{3} \mathrm{O}_{4} \mathrm{NPs}$ had the highest efficiency at $\mathrm{pH} 4$ (Figure 4C). This $\mathrm{pH}$ optimum is consistent with the peroxidaselike activity of $\mathrm{Fe}_{3} \mathrm{O}_{4}$ previously reported by other groups. ${ }^{20,22}$ Therefore, it further supports the role of $\mathrm{Fe}_{3} \mathrm{O}_{4} \mathrm{NPs}$ as a peroxidase. It is also interesting to note the catalytic effect of 
$\mathrm{Fe}_{3} \mathrm{O}_{4}$ NPs occurred at all pH's up to $\mathrm{pH} 8.5$ we tested (Figure $\mathrm{S} 7$ ). Therefore, this reaction can also be carried out under physiological conditions with slightly lower efficiency.

Finally, the effect of ionic strength was tested. We incubated dopamine, $\mathrm{H}_{2} \mathrm{O}_{2}$, and $\mathrm{Fe}_{3} \mathrm{O}_{4} \mathrm{NPs}$ at various $\mathrm{NaCl}$ concentrations and measured the resulting UV-vis absorption and fluorescence spectra (excitation $480 \mathrm{~nm}$ ). The presence of $\mathrm{NaCl}$ enhanced dopamine oxidation as indicated by the increase of the absorption peak at $450 \mathrm{~nm}$ (Figure S8). The fluorescence of the oxidized dopamine also increased by $\sim 2$-fold (Figure 4D). $\mathrm{Fe}_{3} \mathrm{O}_{4} \mathrm{NPs}$ are positively charged at $\mathrm{pH} 4$ (Figure S9), and dopamine has a basic amino group that is protonated at $\mathrm{pH} 4$. Therefore, they experience an electrostatic repulsion at $\mathrm{pH} 4$. A high salt concentration can better screen the charge repulsion between $\mathrm{Fe}_{3} \mathrm{O}_{4} \mathrm{NPs}$ and dopamine, thus facilitating the oxidation reaction. Further adding $\mathrm{MgCl}_{2}$ did not affect the oxidation reaction, suggesting that $\mathrm{NaCl}$ is sufficient for charge screening. Therefore, $\mathrm{NaCl}(50 \mathrm{mM})$ was included from this point on.
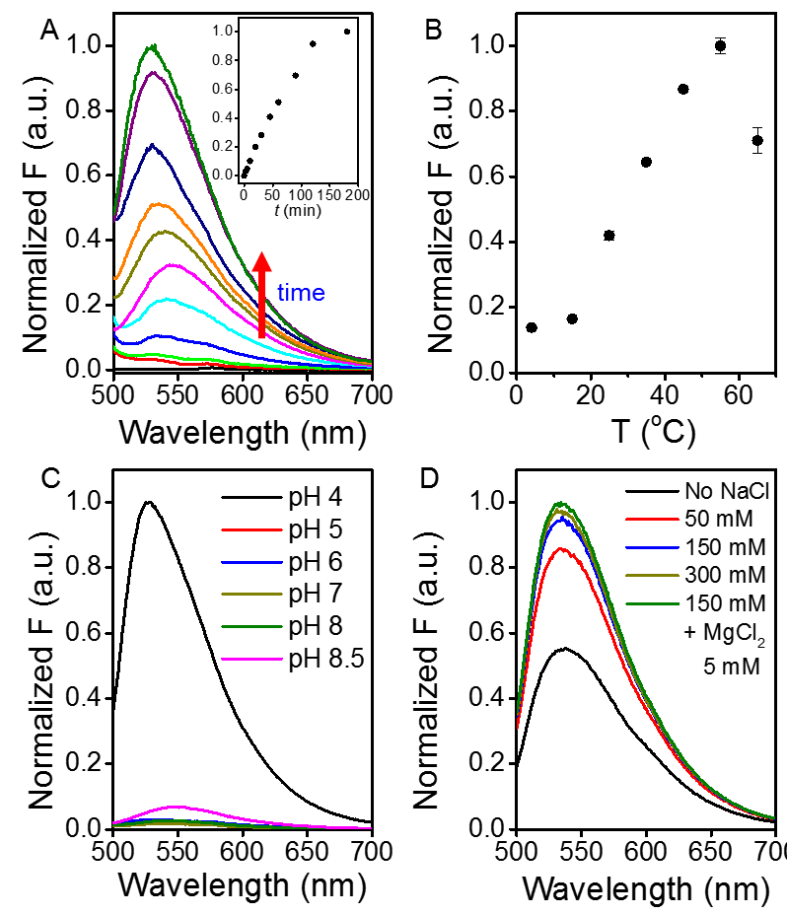
Figure 4. Optimization of reaction conditions for synthesizing FPD. (A) Fluorescence spectra of prepared FPD as a function of time. Effect of (B) temperature, (C) $\mathrm{pH}$, and (D) ionic strength on the activity of $\mathrm{Fe}_{3} \mathrm{O}_{4}$ NPs measured by the FPD emission intensity. The error bars represent standard deviations from three independent measurements.

\section{FPD as a light-up $\mathrm{Zn}^{2+}$ sensor.}

The above work demonstrated a mild method for producing FPD. Next, we aim to study its preliminary applications. Rich in hydroxyl group and amino group, dopamine and polydopamine are good metal ligands. Thus they might sense certain metal ions based on the fluorescence property change. For example, Tseng and co-workers reported that their FPD emitting at $440 \mathrm{~nm}$ can be specifically quenched by $\mathrm{Fe}^{3+} .8$ In the presence of $50 \mu \mathrm{M}$ $\mathrm{Fe}^{3+}$, the fluorescence dropped by about $50 \%$, which was proposed for $\mathrm{Fe}^{3+}$ sensing. However, such 'light-off' sensors are prone to false results with limited room of signal change. The structure of non-fluorescent polydopamine has been a topic of extensive debate,${ }^{34}$ and the structures responsible for fluorescence and the effect of metal ions remain unclear.

Before testing our FPD, we examined the stability of FPD against $\mathrm{pH}$, salt concentration, and alkaline metal ions. The fluorescence was quite stable after overnight incubation (Figure S10). We next tested our FPD with different metal ions, and the fluorescence (excited by $470 \mathrm{~nm}$ LED) was not significantly quenched by any tested metal ion, including $\mathrm{Fe}^{3+}$ (Figure 5A top panel, and Figure 5B).

When excited by a UV lamp at $360 \mathrm{~nm}$ (Figure 5A bottom panel), most samples appeared non-fluorescent. This is consistent with $480 \mathrm{~nm}$ being the optimal excitation 
(Figure S2). Interestingly, a strong blue emission was observed only in the presence of $\mathrm{Zn}^{2+} . \mathrm{Pb}^{2+}$ also resulted a slightly emission. The fluorescence spectra (Figure 5C) show a strong fluorescence peak at $\sim 500 \mathrm{~nm}$ in the presence of $\mathrm{Zn}^{2+}$. Therefore, the species that fluoresce by the $480 \mathrm{~nm}$ excitation is insensitive to metal ions, while another species is responsible for $\mathrm{Zn}^{2+}$ binding. Enhancing the fluorescence yield of organic molecules by $\mathrm{Zn}^{2+}$ has been extensively reported and reviewed, and most are related to photo-induced electron or charge transfer. ${ }^{35}$ We noticed a red shift in the emission peak from $470 \mathrm{~nm}$ to $500 \mathrm{~nm}$ upon $\mathrm{Zn}^{2+}$ binding (Figure 5C). This suggests that the $\mathrm{Zn}^{2+}$ sensing might be related to the photo-induced charge transfer (PCT). The fact that $\mathrm{Zn}^{2+}$ was only sensed by the shorter excitation wavelength suggests that a less conjugated FPD is required, possibly to provide necessary chemical structures for charge transfer. With such an enhancement effect, we reason that a fluorescence "turn-on" sensor may be developed for $\mathrm{Zn}^{2+} . \mathrm{Zn}^{2+}$ is an important metal both in the environment and in biology, and extensive efforts have been made for $\mathrm{Zn}^{2+}$ detection. ${ }^{35,36}$

We examined the kinetics of fluorescence enhancement. A fast fluorescence increase after adding $\mathrm{Zn}^{2+}$ was observed, reaching the plateau within 3 min (Figure 5D). We then plotted the fluorescence intensity at $500 \mathrm{~nm}$ as function of $\mathrm{Zn}^{2+}$ concentration (Figure 5E). A linear trend was obtained up to $5 \mu \mathrm{M} \mathrm{Zn}^{2+}$. The limit of detection (LOD) was calculated to be $60 \mathrm{nM}$ ( $\mathrm{LOD}=3 \sigma /$ slope), where $\sigma$ is the standard deviation of the background. This performance compares favorably with other small molecule based $\mathrm{Zn}^{2+}$ sensors. ${ }^{35}$ Note that the measurement was performed in a complex mixture. It is likely that the sensitivity can be further improved by using the sensitive species alone. Furthermore, 
we tested the $\mathrm{Zn}^{2+}$ detection in diluted serum (Figure S11). A calibration curve was also successfully obtained with a LOD of $600 \mathrm{nM} \mathrm{Zn}^{2+}$.

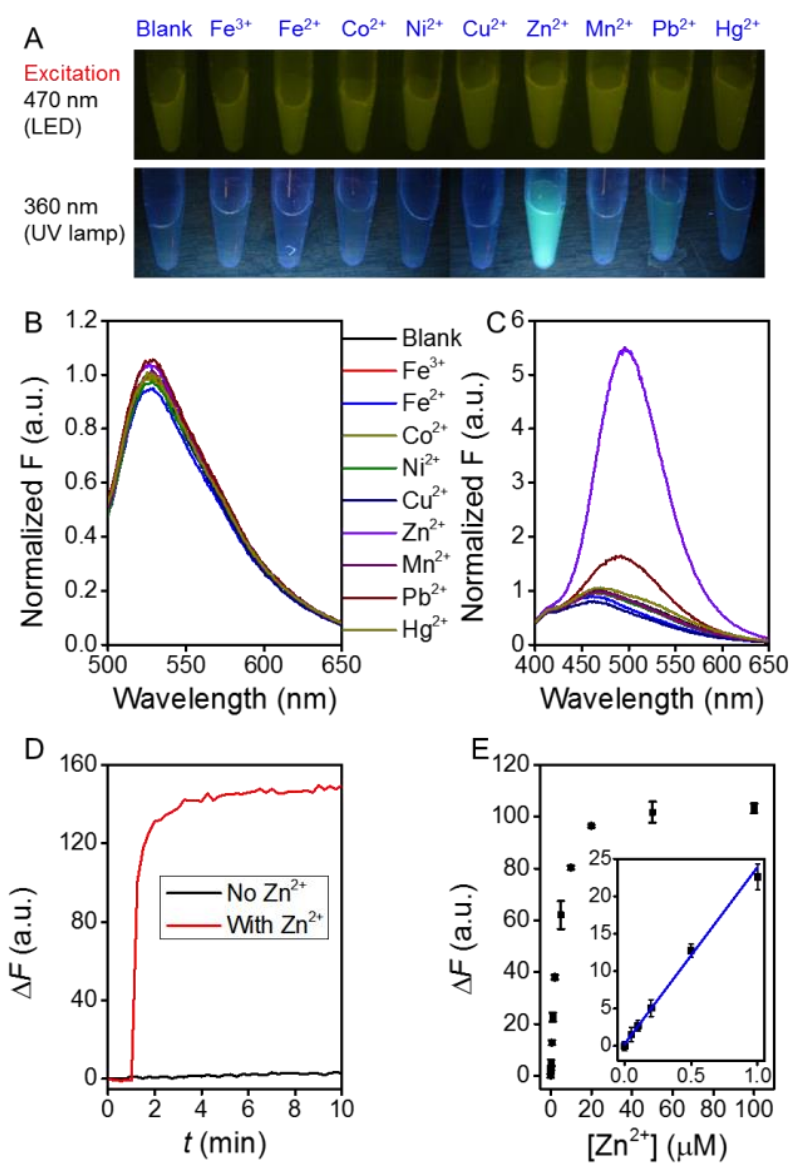

Figure 5. Detection of $\mathrm{Zn}^{2+}$ using FPD. (A) Fluorescence images of FPD in the presence of various metal ions $(10 \mu \mathrm{M})$ under two excitation wavelengths (470 $\mathrm{nm}$ and $360 \mathrm{~nm})$. The corresponding fluorescent spectra under (B) $470 \mathrm{~nm}$ and (C) $360 \mathrm{~nm}$ excitation, respectively. (D) Kinetics of fluorescence variation upon adding $\mathrm{Zn}^{2+}$. (E) Fluorescence intensity as a function of $\mathrm{Zn}^{2+}$ concentration. Inset shows the linear part with a fitting line. The error bars represent standard deviations from three independent measurements. 


\section{Conclusion}

In summary, we demonstrated an efficient nanozyme-assisted method for preparing FPD under mild conditions. The catalysis is likely related to the peroxidase-like activity of $\mathrm{Fe}_{3} \mathrm{O}_{4}$ NPs. While a few NPs can mimic oxidases (directly oxidizing dopamine without $\mathrm{H}_{2} \mathrm{O}_{2}$ ), and most tested nanomaterials have peroxidase-like activity, the preparation of FPD is the best with $\mathrm{Fe}_{3} \mathrm{O}_{4}$ NPs. Therefore, the ability for oxidation is not the only criteria for the production of FPD. The FPD did not coat the $\mathrm{Fe}_{3} \mathrm{O}_{4}$ surface to inhibit its further reaction, and the nanozyme can be recycled for 10 times still retaining nearly full activity. The reaction conditions have been optimized in terms of time, temperature, $\mathrm{pH}$ and ionic strength, and these optimization efforts also provide new fundamental insights. Finally, we achieved highly sensitive $\mathrm{Zn}^{2+}$ detection based on the fluorescence enhancement of FPD at $360 \mathrm{~nm}$ excitation (but not with $470 \mathrm{~nm}$ excitation). In this case, only a sub-population of the product is sensitive to $\mathrm{Zn}^{2+}$. This work indicates that a lot remains to be explored on polydopamine in terms of synthesis, characterization, and application. Nanozymes might play a unique role in this process based on their surface chemistry, robustness, and high catalytic efficiency. This work has found a new direction of using nanozymes for making new materials. This should be a promising application since nanozymes can survive harsh conditions that might be required for such synthesis.

\section{Acknowledgement}

Funding for this work is from the Natural Science and Engineering Research Council of Canada (NSERC). H. Xiao is supported by a Chinese Scholarship Council (CSC) scholarship. 
Electronic Supplementary Information (ESI) available: [methods, TEM, $\zeta$-potential, and original fluorescence spectra]. See DOI: 10.1039/

\section{References}

1. $\quad$ Y. Liu, K. Ai and L. Lu, Chem. Rev., 2014, 114, 5057-5115.

2. H. Lee, S. M. Dellatore, W. M. Miller and P. B. Messersmith, Science, 2007, 318, 426-430.

3. K. Liu, W.-Z. Wei, J.-X. Zeng, X.-Y. Liu and Y.-P. Gao, Anal. Bioanal. Chem., 2006, 385, 724-729.

4. C. K. K. Choi, J. Li, K. Wei, Y. J. Xu, L. W. C. Ho, M. Zhu, K. K. W. To, C. H. J. Choi and L. Bian, J. Am. Chem. Soc., 2015, 137, 7337-7346.

5. X. Zhang, S. Wang, L. Xu, L. Feng, Y. Ji, L. Tao, S. Li and Y. Wei, Nanoscale, 2012, 4, 5581-5584.

6. X. Chen, Y. Yan, M. Müllner, M. P. van Koeverden, K. F. Noi, W. Zhu and F. Caruso, Langmuir, 2014, 30, 2921-2925.

7. A. Yildirim and M. Bayindir, Anal. Chem., 2014, 86, 5508-5512.

8. J.-H. Lin, C.-J. Yu, Y.-C. Yang and W.-L. Tseng, Phys. Chem. Chem. Phys., 2015, 17, 15124-15130.

9. $\quad$ N. A. Kotov, Science, 2010, 330, 188-189.

10. H. Wei and E. Wang, Chem. Soc. Rev., 2013, 42, 6060-6093.

11. Y. Lin, J. Ren and X. Qu, Acc. Chem. Res., 2014, 47, 1097-1105.

12. X. Wang, Y. Hu and H. Wei, Inorg. Chem. Front., 2016, 3, 41-60.

13. M. Comotti, C. Della Pina, R. Matarrese and M. Rossi, Angew. Chem. Int. Ed., 2004, 43, 5812-5815.

14. X. Zheng, Q. Liu, C. Jing, Y. Li, D. Li, W. Luo, Y. Wen, Y. He, Q. Huang, Y.-T. Long and C. Fan, Angew. Chem. Int. Ed., 2011, 50, 11994-11998.

15. Y. Liu, H. Wu, M. Li, J.-J. Yin and Z. Nie, Nanoscale, 2014, 6, 11904-11910.

16. Y. Song, X. Wang, C. Zhao, K. Qu, J. Ren and X. Qu, Chem. - Eur. J., 2010, 16, 3617-3621.

17. Y. Song, K. Qu, C. Zhao, J. Ren and X. Qu, Adv. Mater., 2010, 22, 2206-2210.

18. H. Sun, A. Zhao, N. Gao, K. Li, J. Ren and X. Qu, Angew. Chem. Int. Ed., 2015, 54, 7176-7180.

19. C. Xu and X. Qu, NPG Asia Mater., 2014, 6, e90.

20. L. Gao, J. Zhuang, L. Nie, J. Zhang, Y. Zhang, N. Gu, T. Wang, J. Feng, D. Yang, S. Perrett and X. Yan, Nat. Nanotechnol., 2007, 2, 577-583.

21. B. Liu, Z. Sun, P.-J. J. Huang and J. Liu, J. Am. Chem. Soc., 2015, 137, 1290-1295.

22. B. Liu and J. Liu, Nanoscale, 2015, 7, 13831-13835. 
23. Y. Zhang, Z. Wang, X. Li, L. Wang, M. Yin, L. Wang, N. Chen, C. Fan and H. Song, Adv. Mater., 2016, 28, 1387-1393.

24. I. Celardo, J. Z. Pedersen, E. Traversa and L. Ghibelli, Nanoscale, 2011, 3, 14111420.

25. M. Liang, K. Fan, Y. Pan, H. Jiang, F. Wang, D. Yang, D. Lu, J. Feng, J. Zhao, L. Yang and X. Yan, Anal. Chem., 2013, 85, 308-312.

26. J. Zhuang, J. Zhang, L. Gao, Y. Zhang, N. Gu, J. Feng, D. Yang and X. Yan, Mater. Lett., 2008, 62, 3972-3974.

27. H. Wei and E. Wang, Anal. Chem., 2008, 80, 2250-2254.

28. D. Duan, K. Fan, D. Zhang, S. Tan, M. Liang, Y. Liu, J. Zhang, P. Zhang, W. Liu, X. Qiu, G. P. Kobinger, G. Fu Gao and X. Yan, Biosens. Bioelectron., 2015, 74, 134-141.

29. E. Golub, H. B. Albada, W.-C. Liao, Y. Biniuri and I. Willner, J. Am. Chem. Soc., 2016, 138, 164-172.

30. A. Asati, S. Santra, C. Kaittanis, S. Nath and J. M. Perez, Angew. Chem. Int. Ed., 2009, 121, 2344-2348.

31. J. Liu and Y. Lu, Nat. Protoc., 2006, 1, 246-252.

32. Y. Tan, W. Deng, Y. Li, Z. Huang, Y. Meng, Q. Xie, M. Ma and S. Yao, J. Phys. Chem. B, 2010, 114, 5016-5024.

33. Y. Liu, D. L. Purich, C. Wu, Y. Wu, T. Chen, C. Cui, L. Zhang, S. Cansiz, W. Hou, Y. Wang, S. Yang and W. Tan, J. Am. Chem. Soc., 2015, 137, 14952-14958.

34. D. R. Dreyer, D. J. Miller, B. D. Freeman, D. R. Paul and C. W. Bielawski, Langmuir, 2012, 28, 6428-6435.

35. P. Jiang and Z. Guo, Coord. Chem. Rev., 2004, 248, 205-229.

36. J. Peng, W. Xu, C. L. Teoh, S. Han, B. Kim, A. Samanta, J. C. Er, L. Wang, L. Yuan, X. Liu and Y.-T. Chang, J. Am. Chem. Soc., 2015, 137, 2336-2342. 